\title{
Construction teaching mode of mechanical drawing from the engineering perspective
}

\author{
Binghui $\mathrm{Wu}^{1, \mathrm{a}}$, Jianjun $\mathrm{Xi}^{2, \mathrm{~b}}$ and $\mathrm{Na}$ Gong ${ }^{2, \mathrm{c}}$ \\ ${ }^{1}$ Shanghai university of electric power, Shanghai, China \\ ${ }^{2}$ Harbin institute of technology, Harbin, Heilongjiang, China \\ awubinghui72@163.com, ${ }^{b} x j j 63 @ 163 . c o m,{ }^{c}$ gongna@hit.edu.cn
}

Keywords: mechanical drawing; practice ability; three-dimensional modeling.

\begin{abstract}
Along with the goal of higher education promulgated, in which the cultivation of applied talents was proposed, the cultivation of students' engineering capabilities attracted the attention of higher educators increasingly. Engineering training teaching mode of mechanical drawing was proposed, which focus on training students to solve practical problems. In this mode, the ability of engineering practice is the focus, a variety of teaching resources as the support, and three-dimensional modeling design are totally integrated.
\end{abstract}

\section{Introduction}

In a very long time, training objectives of mechanical drawing are targeted at students' drawing skills and the ability to interpret blueprints. Engineering capabilities of students are ignored.

In the context of global economic integration, China's engineering education mode must be adapted with the rapid development of engineering technology. Since the late 20th century, higher education in China has been transformed from elite education to mass education formula successfully [1]. With the goal of higher education promulgated, the cultivation of students' engineering capabilities attracted the attention of higher educators more and more. Mechanical Drawing is the first course students contact since they enter the university, which is closely related with the professional courses. To help students transfer their learning mode from the examination-purpose to apply-purpose as soon as possible, establishes of engineering consciousness should begin when the students are freshmen. The transfer of learning mode will improve the teaching effectiveness of subsequent professional courses greatly.

\section{Set teaching content of mechanical engineering drawing from the perspective}

The course is also a basic course, and the students do not have any knowledge of professional before. Physical and views for students are unfamiliar, and knowledge of mechanical parts is almost a blank. Students feel cartography boring and difficult to learn [2]. Thus, engineering examples should be introduced into the teaching content. Intersection of two cylinders was shown in Figure 1, and the intersecting lines of its surface are difficult for students to grasp and understand. For this reason, the actual structure shown in Figure 2 into the classroom, and then explain its projection through theoretical analysis approach can strengthen students' understanding of intersecting lines .

When explaining parts and assembly drawings, the engineering example was introduced into the course appropriately, and students were divided into groups to measuring and sketching the components. Aluminum alloy parts were employed here, which is shown in Figure 3. By measuring and sketching the actual parts, perceptual knowledge of engineering part in student's brain was reinforced. Student's learning initiative was improved simultaneously. Three-dimensional simulation or real video mode also can be used as material in the class to show actual production scenarios. It can deepen the understanding of principles of machine operation, and students' attention is strongly attracted. All these methods can develop the students' horizons, expand their imagination and enhance the ability of students' innovative designs. Expansion of the course is provided. 


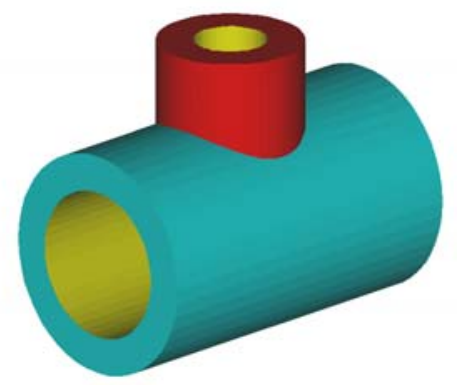

Figure 1 intersecting line model

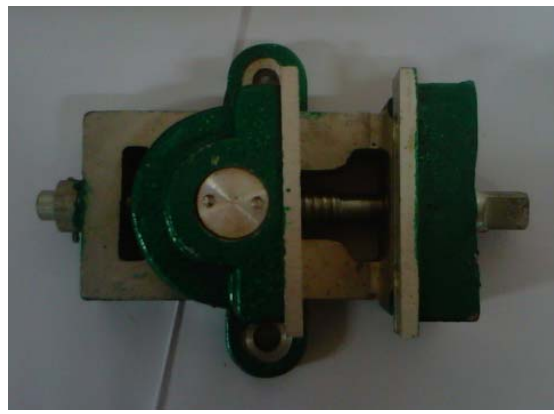

a) Machine vice

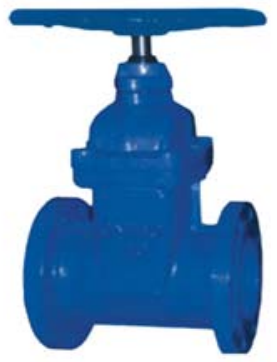

Figure 2 intersecting line Projects

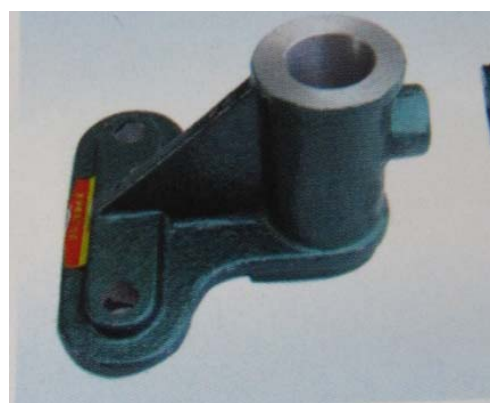

b) Fork type parts

Figure 3 Part and assembly for measuring and sketching

Organization and production of animation and multimedia image data for typical examples into the classroom provide a wealth of stories. Move the project site into the classroom originally out of reach, and transfer the boring theory becomes vivid examples. Increase the instance in the practice when teaching assembly drawing. It can improve students' learning motivation and also can make it clear that the mechanical drawing play an important role in the production.

\section{Employ three-dimensional design as the main line to mastery}

The main aim of mechanical drawing is to train the ability of students to interpret the engineering drawings and the ability of drawing. Drawing and interpret drawing don't work without the space imagination. Therefore, the ability to develop substantive drawing is to cultivate students' ability of space imagination, analytical ability and communication skills. Abilities of the three complementary are exist side by side. The imagination stands the core position among these three. To this end, repeated training between the view and the physical should be practiced from easy to difficult and step by step in the learning process. The combination of entities is varied, and mechanical parts are more different. While charts are no longer used in many schools, instead of using the courseware, there are also still static and flat natures of the majority content in courseware that can't play a good role in establishing space imagination of students [3].

With the development of computer hardware and software technology, of three-dimensional design is increasingly being accepted by the designer. Utilizing advantages of three-dimensional software, organism combination of computer graphics and traditional teaching content of organic integration, abstract knowledge into the things that students can observe, analyze and imagine. Using the three-dimensional graphics software-SolidWorks flexible in teaching mechanical drawing course can make complex spatial geometry intuitive, concrete and visualization. It can help students understand and remember the knowledge. Thus, the interest of motive learning can be cultivated gradually. Also the mental weariness is eliminated. This method will improve teaching effectiveness in mechanical drawing course so as to achieve better teaching results. Figure 4 shows the solid model of a complex body, which should be express by a half-section. 
Using 3D modeling software in the classroom when teaching this course can achieve visual effects and reduce teaching costs. The application of three-dimensional graphics software realizes leaps and bounds. The teacher can build teaching model at the site instantly. There are no teaching costs, only high teaching efficiency and can achieve dynamic conversion. Students' interest in learning is greatly improved, and the thinking ability of students is developed in the entertainment. It meets disciplines of mechanical drawing course and can improve students' ability to interpret drawings.

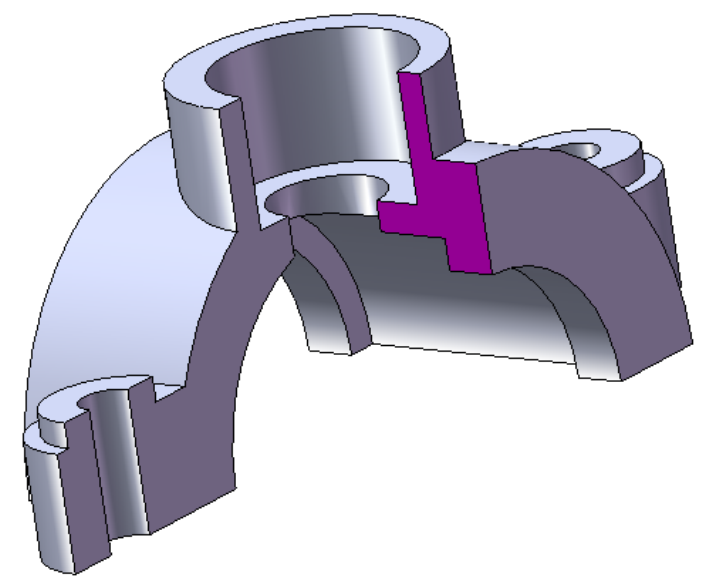

Figure 4 Half-section of a composite body

\section{Lay equal stress on computer graphics and traditional teaching; pursue the training of freehand drawing capabilities}

Emphasis on undergraduate engineering talent training program should reflect the comprehensive features of engineering knowledge, engineering, quality and engineering ability. Therefore, the design of practice teaching should be closely combined with practical engineering. Drawing with ruler is the basis, which enables the students to understand the basic principles of national standards well and understand the principle rule of drawing. By the training of ruler drawing, the ability of space imagination and rigorous attitude can be cultured. As computer graphics has some advantages as high speed, high precision and easy to modify and so on.

The ruler drawing in practice is gradually replaced by computer graphics ${ }^{[4]}$. However, freehand drawing conceived an irreplaceable role in the product design. Sketch without rulers has the advantage of less limitation, fast, efficient and so on, which will help the designer draw in the field. So sketching without rulers has very strong engineering practicality. At the beginning, through freehand drawing to get roughly idea, and next three-dimensional model was built up, then display and interactive modification. Such step can save design time and improve design efficiency. In order to improve the adaptability of students into business, freehand drawing becomes one of only sketch the main teaching engineering graphics training.

Containing the capabilities of ruler drawing, CAD drawings and freehand drawing, such comprehensive training can enhance students' ability to hand-painted and image thinking ability. This also takes into account their ability to deal with the practical problems after employment. Simultaneously it enables students to experience the advanced modern technology.

\section{Evaluation of Teaching Effectiveness}

Teaching effectiveness of mechanical drawing course is reflected in the students' curriculum design and graduate design. From 2010 onwards, this innovative teaching model has been implemented in one-third of the class among the school.

In the $3^{\text {th }}$ "The Shangtu Cup", our students achieved excellent results. We obtained the first degree groups prize in a two-dimensional computer graphics in shanghai. In the sixth "Higher 
Education Cup" competition, we get the second groups prize nationally. Test scores, awards, etc. are model a positive affirmation of teaching. But more importantly, through this way can mobilize the initiative of students to improve their ability to solve engineering problems.

\section{Summary}

This paper presents an engineering training teaching mode for mechanical drawing. It focuses on the engineering practice ability, and fully integrates three-dimensional design and class-teaching. Teaching objectives, course content and teaching organizational structure are reformed. Fully implement the teaching mode of innovative practice based and supplemented with class-teaching from the choreography, lectures and other aspects of freehand drawing. Let the students get and feel engineering experience through a variety of channels. Enable students to solve practical problems from the perspective, to understand the learning content and to enhance learning interest.

\section{Acknowledgements}

This work was financially supported by the Shanghai Municipal Education Commission (20135302).

\section{References}

[1] X. F. Wang. Reading a few problems in the U.S. VM ( mechanical ) drawing discussion. Construction Machinery Technology \& Management. No. 7 (2007) p. 117-122

[2] Xiao Tang beginning . Mapping System of competency practical set of coordinated development of knowledge . Journal of Engineering Graphics. No.5, Vol. 33 (2012), p.137-140

[3] Lili . Application and Practice three-dimensional graphics software in the " Mechanical Drawing " Teaching. Weifang College. . No.2, Vol. 10 (2010), p. 155-157.

[4] Dingqiao , WU Ya-hong, Maw-Shen Lee . Engineering drawing and CAD drawing curriculum integration of research and practice teaching [J]. Mechanical Management and Development. No.2, (2011), p. 185-186.

[5] Yuan lina, Wang ling. Teaching method reform of the drawing course by integrating CDIO mode[C]. ICCSE 2011 - 6th International Conference on Computer Science and Education, Final Program and Proceedings. 2011, p 1301-1302. 